\title{
Nanosized Unsupported and Alumina-Supported Ceria-Zirconia and Ceria-Terbia Solid Solutions for CO Oxidation
}

\author{
M. Reddy BENJARAM*, Thrimurthulu GODE, Lakshmi KATTA \\ Inorganic and Physical Chemistry Division, Indian Institute of Chemical Technology, Hyderabad 500 607, India
}

\begin{abstract}
Ceria-zirconia (CZ) and ceria-terbia (CT) and alumina-supported ceria-zirconia (CZA) and ceria-terbia (CTA) solid solutions were synthesized by coprecipitation and deposition precipitation methods, respectively. Structural characteristics and catalytic activity of the synthesized samples have been investigated using X-ray diffraction (XRD), high resolution transmission electron microscopy (HRTEM), X-ray photoelectron spectroscopy (XPS), Raman spectroscopy (RS), and Brunauer-Emmett-Teller (BET) surface area measurements. To evaluate the catalytic properties, total oxygen storage capacity and $\mathrm{CO}$ oxidation activity measurements were carried out. The XRD analyses revealed the formation of $\mathrm{Ce}_{0.75} \mathrm{Zr}_{0.25} \mathrm{O}_{2}$ phase for $\mathrm{CZ}$ and $\mathrm{Ce}_{0.5} \mathrm{Zr}_{0.5} \mathrm{O}_{2}$ and $\mathrm{Ce}_{0.6} \mathrm{Zr}_{0.4} \mathrm{O}_{2}$ phases for CZA samples, respectively. While the formation of only $\mathrm{Ce}_{0.8} \mathrm{~Tb}_{0.2} \mathrm{O}_{2-\delta}$ phase was noted for both $\mathrm{CT}$ and CTA samples. All the supported and unsupported samples adopted a fluorite-type structure and exhibited cell parameters with respect to Vegard's rule. The HRTEM results indicated well-dispersed particles of the size around 5 $\mathrm{nm}$. The RS measurements suggested the presence of oxygen vacancies due to defective structure formation. The XPS studies revealed the presence of cerium in both $\mathrm{Ce}^{4+}$ and $\mathrm{Ce}^{3+}$ oxidation states in different proportions. It was found that $\mathrm{CO}$ oxidation for CTA occurs at very much lower temperature than CT, CZ, and CZA samples. Details of these findings by correlating with the structural characterization studies are consolidated.
\end{abstract}

Key words: ceria; zirconia; terbia; alumina-support; deposition coprecipitation; CO oxidation

CLC number: O643 Document code: A

Received 7 March 2011. Accepted 31 March 2011.

*Corresponding author.Tel: +91-40-27191714; Fax: +91-40-27160921; E-mail: bmreddy@iict.res.in; mreddyb@yahoo.com

This work was supported by Council of Scientific and Industrial Research (CSIR), New Delhi, India.

English edition available online at Elsevier ScienceDirect (http://www.sciencedirect.com/science/journal/18722067).

Emissions from vehicles and industrial plants are of great concern due to the damages they have forced on the environment, such as acid rain and photochemical smog [1]. Over the past several years, $\mathrm{CeO}_{2}$ has come under intense scrutiny as a promoter in important industrial or environmentally friendly reactions, for example automotive exhaust gas purification, methane reforming processes, and water-gas shift reaction, etc. due to its structure and divergent properties [2]. In $\mathrm{CeO}_{2}$ with fluorite type cubic structure, the $\mathrm{Ce}^{4+} \leftrightarrow \mathrm{Ce}^{3+}$ redox cycle is facile and oxygen mobility in the crystallographic structure is prompt. However, the major problem associated with pure $\mathrm{CeO}_{2}$ is the loss of oxygen storage capacity (OSC) due to a reduction in surface area upon thermal treatment. The success of oxygen storage process based on ceria is due to ability to change of oxidation state during operation (i.e. $\mathrm{CeO}_{2}$ to $\mathrm{CeO}_{2-x}$ ) maintaining structural integrity, thus allowing oxygen uptake and release to occur smoothly [3]. Recently, much attention is devoted to nanocrystalline binary Ce- $\mathrm{Ln}-\mathrm{O}(\mathrm{Ln}=\mathrm{RE}$ and transition metal ions) oxides, which show improved performance in comparison with their individual microcrystalline counterparts. It is known that by introducing different elements into the $\mathrm{CeO}_{2}$ lattice, stabilization of the structure against sintering along with enhanced reducibility is achieved as a result of the creation of structural defects in the lattice. Substitution of ceria induces distortion of the $\mathrm{O}^{2-}$ sublattice in the solid solutions which permit a higher mobility of lattice oxygen, thus the reduction occurs not only on the surface but also extends deep into the bulk. Especially, ceria nanostructures doped with $\mathrm{Zr}^{4+}, \mathrm{Ti}^{4+}, \mathrm{Hf}^{4+}, \mathrm{La}^{3+}, \mathrm{Tb}^{3+/ 4+}$, and $\mathrm{Pr}^{3+/ 4+}$, ions have been extensively investigated for various chemical reactions and proven to be superior in terms of both thermal/textural behaviours as well as catalytic activity (OSC and $\mathrm{CO}$ oxidation) compared with $\mathrm{CeO}_{2}$ alone [4-9]. Particularly, the use of variable valence dopants has attracted lot of interest and it is thought that the addition of redox ions like $\mathrm{Tb}, \mathrm{Pr}$, etc. enhance the catalytic activity proceeding through an alternate route $[10,11]$. Based on the above fact, we have undertaken the present investigation. In this comprehensive study a systematic comparison has been attempted between ceria-zirconia and ceria-terbia solid solutions. Accordingly, we have prepared ceria-terbia mixed oxide and compared with widely established ceria-zirconia. Interestingly, the chemically inert and thermally stable sup- 
ports over ceria-based mixed oxides, as a new generation of oxygen storage capacity systems, have been uniformly ascertained in many studies [12]. Recently, we have also shown that alumina-supported ceria-zirconia exhibit a strong influence on the thermal stability and redox behaviour of $\mathrm{Ce}_{x} \mathrm{Zr}_{1-x} \mathrm{O}_{2}$ solid solutions over other supports [13]. Motivated by these facts, alumina-supported ceria-terbia solid solutions were synthesized by means of deposition precipitation method and characterized using various techniques such as, Brunauer-Emmett-Teller (BET) surface area, X-ray diffraction (XRD), Raman spectroscopy (RS), transmission electron microscopy (TEM), and X-ray photoelectron spectroscopy (XPS). The synthesized materials are also examined by performing total oxygen storage capacity (TOSC) and CO oxidation activity. Combined with characterizations, a possible reason for the observed excellent $\mathrm{CO}$ activity for alumina-supported ceria-terbia has been discussed.

\section{Experimental}

\subsection{Catalyst preparation}

Ceria-zirconia ( $\mathrm{CZ}, 50: 50$ molar ratio based on oxides) and ceria-terbia (CT, 80:20 molar ratio based on oxides), and alumina-supported ceria-zirconia (CZA, 100:50:50 molar ratio based on oxides) and ceria-terbia (CTA, 100:80:20 molar ratio based on oxides) samples were prepared by coprecipitation and deposition precipitation methods, respectively, by using dilute aqueous $\mathrm{NH}_{3}$ solution as a precipitating agent. For mixed oxides preparation, required amounts of ammonium cerium(IV) nitrate (GR, Loba Chemie) and zirconium nitrate (AR, Fluka) or terbium(III) nitrate (AR, Aldrich) were dissolved separately, each in $500 \mathrm{ml}$ of deionized water then mixed together and stirred continuously for $1 \mathrm{~h}$. Aqueous $\mathrm{NH}_{3}$ solution was added dropwise at a flow rate of $30 \mathrm{ml} / \mathrm{min}$, to the mixture solution until $\mathrm{pH}$ $\sim 8.5$, under vigorous stirring. For supported samples, desired quantity of powdered $\gamma-\mathrm{Al}_{2} \mathrm{O}_{3}$ (Harshaw) having a specific surface area of $127 \mathrm{~m}^{2} / \mathrm{g}$ was first dispersed in about $2000 \mathrm{ml}$ of deionized water and stirred for $2 \mathrm{~h}$. Required amounts of ammonium cerium(IV) nitrate and zirconium nitrate or terbium(III) nitrate were dissolved separately in $500 \mathrm{ml}$ deionized water and mixed together. Then under stirring condition, the mixture solution was added thoroughly to the above solution and the whole mixture was diluted to $4000 \mathrm{ml}$ with deionized water. The stirring was continued for another $1 \mathrm{~h}$. Aqueous $\mathrm{NH}_{3}$ solution was added dropwise at a flow rate of $30 \mathrm{ml} / \mathrm{min}$ to the mixture until $\mathrm{pH}$ $\sim 8.5$ under vigorous stirring. The obtained precipitates were filtered off, washed several times with deionized water, and oven-dried at $393 \mathrm{~K}$ for $12 \mathrm{~h}$, then subsequently calcined at
$773 \mathrm{~K}$ for $5 \mathrm{~h}$ in air atmosphere. After cooling, the solid residues were ground with a ceramic mortar and pestle until fine powders were obtained.

\subsection{Catalyst characterization}

The XRD data were acquired on a Rigaku Multiflex instrument equipped with nickel-filtered $\mathrm{Cu} K_{\alpha}(0.15418 \mathrm{~nm})$ radiation source and a scintillation counter detector. The step size and the time per step were, respectively, fixed at $0.02^{\circ}$ and $1 \mathrm{~s}$ in the range of $12^{\circ}-80^{\circ}$. The mean crystallite size of the solid solution phases was estimated with the help of Scherrer equation from line broadening, and the lattice parameter was calculated by a standard cubic indexation method using the intensity of the most prominent peak (111). The RS were obtained at room temperature using a LabRam HR800UV Raman spectrometer (Horiba Jobin-Yvon) fitted with a confocal microscope and liquid-nitrogen cooled charge-coupled device (CCD) detector. Samples were excited either with $325 \mathrm{~nm}$ of a He-Cd laser (Melles Griot) which was focused on the sample under the microscope with the diameter of the analyzed spot being $\sim 1$ $\mu \mathrm{m}$. The acquisition time was adjusted according to the intensity of Raman scattering. The wavenumber values reported from the spectra are accurate to within $1 \mathrm{~cm}^{-1}$.

Specific surface areas of the samples were determined by a single point BET analysis of the nitrogen adsorption isotherms at liquid $\mathrm{N}_{2}$ temperature ( $77 \mathrm{~K}$ ) over a Gemini 2360 instrument via a thermal conductivity detector. Prior to the experiment, samples were degassed at $393 \mathrm{~K}$ for $2 \mathrm{~h}$ to remove any surface adsorbed residual moisture. Surface area is obtained by using the desorption data. The high resolution transmission electron microscopy (HRTEM) studies were made on a JEM-2010 instrument (JEOL) equipped with a slow-scan CCD camera and at an accelerating voltage of $200 \mathrm{kV}$. Samples for HRTEM were prepared by crushing the materials in an agate mortar and dispersing them ultrasonically in ethyl alcohol. After dispersion, a droplet was deposited on a copper grid supporting a perforated carbon film and allowed to dry. The specimen was examined under vacuum at room temperature.

The XPS analysis was performed using a ESCA 3400 spectrometer (Shimadzu). The X-ray source utilized was $\mathrm{Mg} K_{\alpha}(1253.6 \mathrm{eV})$ radiation. The analysis was done at room temperature and pressures were typically in the order of less than $1 \times 10^{-8} \mathrm{~Pa}$ to avoid large amount of noise in the spectra from contaminates. Charging of the samples was minimized by referencing the spectra to the $\mathrm{C} 1 s$ line at $E_{\mathrm{b}}=$ $284.6 \mathrm{eV}$. Samples were outgassed overnight in a vacuum oven before XPS measurements.

\subsection{Catalyst evaluation}


A thermogravimetric method, essentially similar to that described previously elsewhere, was used to determine the TOSC by the oxygen release characteristics of the samples in the temperature region 573-1073 K [14]. The change in the weight of the sample was monitored by thermogravimetry (TG) under cyclic heat treatments in flowing nitrogen or dry air. A commercial Netzsch TG-DTA analyzer (Sta 409 PC Luxx, Germany) was employed for this purpose. The heat cycle consisted of heating the sample to $1073 \mathrm{~K}$, cooling to $423 \mathrm{~K}$, and again heating to $1073 \mathrm{~K}$. All heating and cooling rates were maintained at $5 \mathrm{~K} / \mathrm{min}$. The weight loss of the sample during the second heating cycle was used to measure the oxygen release properties [14].

The catalytic activity of the sample for oxidation of $\mathrm{CO}$ was conducted at normal pressure (one atmosphere) in the temperature range $300-773 \mathrm{~K}$ in a fixed bed microreactor under the temperature ramp of $5 \mathrm{~K} / \mathrm{min}$. Approximately 100 mg catalyst sample (250-355 $\mu \mathrm{m}$ sieve fraction) was diluted with quartz particles of the same sieve fraction and was placed in a quartz reactor and its ends plugged with ceramic wool. Reaction temperature was monitored using a thermocouple placed in the hollow part of the reactor. The following gases and gas mixtures were used (supplied by air liquide): $9.98 \% \mathrm{CO}(99.997 \%)$ and $10.2 \% \mathrm{O}_{2}$ (> 99.995\%) with argon ( $>99.999 \%)$ as balance. The total flow rates maintained by three mass flow controllers were in the range of $50-60 \mathrm{ml} / \mathrm{min}$ (milliliters normalized to $273.15 \mathrm{~K}$ and $1 \times$ $10^{5} \mathrm{~Pa}$ ). The $\mathrm{CO}$ and $\mathrm{CO}_{2}$ gas concentrations were measured using an Uras 14 infrared analyzer module, and the $\mathrm{O}_{2}$ concentration was measured using a Magnos 16 analyzer (Hartmann\&Braun). Prior to oxidation of $\mathrm{CO}$, the catalyst was heated to $773 \mathrm{~K}$ in the $10.2 \% \mathrm{O}_{2}-89.8 \%$ Ar gas mixture, using a heating ramp of $10 \mathrm{~K} / \mathrm{min}$, and kept at the final temperature for $1 \mathrm{~h}$. The oxidized sample was then purged in argon to avoid gas phase reaction and cooled to the desired starting temperature. The $\mathrm{CO} / \mathrm{O}_{2}$ reactant feed ratio was 1 , and partial pressures of $\mathrm{CO}$ and $\mathrm{O}_{2}$ were in the range of $1 \times 10^{3} \mathrm{~Pa}$.

\section{Results and discussion}

\subsection{XRD result}

The XRD patterns of CZ, CT, CZA, and CTA samples calcined at $773 \mathrm{~K}$ are shown in Fig. 1. For comparison purpose, XRD profile of pure cerium oxide calcined at $773 \mathrm{~K}$ and $\gamma-\mathrm{Al}_{2} \mathrm{O}_{3}$ are included in the figure. The diffraction peaks of the samples could be indexed to (111), (200), (220), (311), (222), (400), and (331) crystal faces corresponding to a characteristic fluorite type structure of ceria. All XRD features clearly indicated the formation of solid solution between ceria and dopant ion $(\mathrm{Zr}$ or $\mathrm{Tb})$ and correspond to

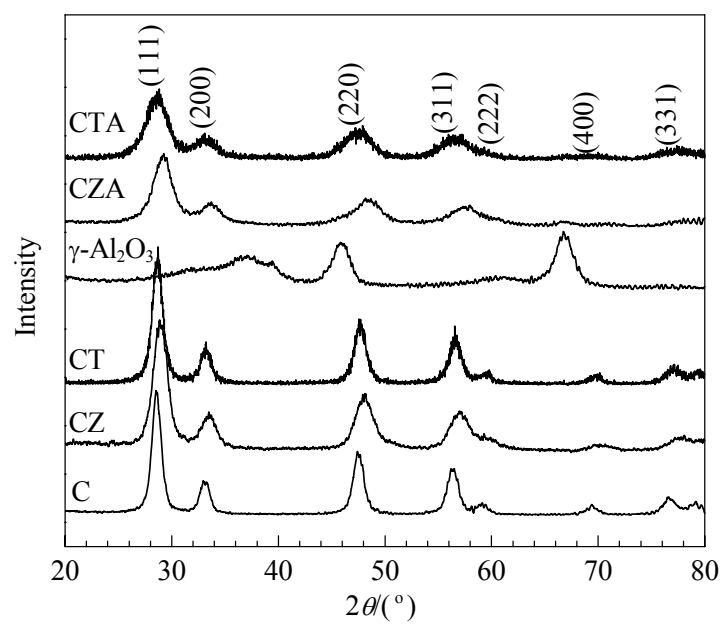

Fig. 1. Powder XRD patterns of ceria (C), CZ, CT, CZA, and CTA samples calcined at $773 \mathrm{~K}$ and $\gamma-\mathrm{Al}_{2} \mathrm{O}_{3}$.

solely fluorite type lattice. Interestingly, there are no diffraction peaks corresponding to alumina in the supported samples, indicating amorphous nature of the support. The $\mathrm{XRD}$ analysis revealed that in the case of $\mathrm{CZ}$ solid solution, the observed phase composition corresponds to $\mathrm{Ce}_{0.75} \mathrm{Zr}_{0.25} \mathrm{O}_{2}$ (PDF-ICDD 28-0271) instead of the expected $\mathrm{Ce}_{0.5} \mathrm{Zr}_{0.5} \mathrm{O}_{2}$ composition, which indicates that all the $\mathrm{Zr}$ cations are not completely incorporated into the $\mathrm{CeO}_{2}$ lattice and there could be the presence of some amount of amorphous $\mathrm{ZrO}_{2}$ at the grain boundaries of $\mathrm{CZ}$ particles. While in the case of CZA solid solution, the observed phase composition was $\mathrm{Ce}_{0.6} \mathrm{Zr}_{0.4} \mathrm{O}_{2}$ (PDF-ICDD38-1439) and $\mathrm{Ce}_{0.5} \mathrm{Zr}_{0.5} \mathrm{O}_{2}$ (PDF-ICDD38-1436) indicating that alumina support facilitated the incorporation of more $\mathrm{Zr}$ atoms into the ceria lattice. In the case of Tb doping, an identical composition $\mathrm{Ce}_{0.8} \mathrm{~Tb}_{0.2} \mathrm{O}_{2-\delta}$ was observed in both $\mathrm{CT}$ and CTA solid solutions [15].

The diffraction peaks became broad after the incorporation of $\mathrm{Zr}$ or $\mathrm{Tb}$ cations into the ceria lattice which further broadened when deposited on the alumina support. This observation indicated that the crystallite size of the ceria is becoming smaller and smaller by the incorporation of dopant and in turn deposition on to the support. The average crystallite sizes and lattice parameters of all the mixed oxides are presented in Table 1. From the table it is also clear that the change in the lattice parameter is obvious fallowing the Vegard's rule due to incorporation of dopant ions with indifferent ionic radius with reference to the cerium ion [16]. The calculated lattice parameter value for $\mathrm{CZ}$ solid solution revealed incorporation of smaller zirconium cations $\left(\mathrm{Zr}^{4+}\right)$ into the ceria lattice having smaller cell dimension than ceria. The lattice parameters obtained for the CT solid solution are larger than expected if the whole terbium is present as $\mathrm{Tb}^{4+}$, hence, a part of terbium must be present as 
Table 1 BET surface area, crystallite size, and lattice parameter of the $\mathrm{C}, \mathrm{CZ}, \mathrm{CT}, \mathrm{CZA}$, and CTA samples calcined at $773 \mathrm{~K}$

\begin{tabular}{lcccc}
\hline Sample & $\begin{array}{c}\text { Surface area } \\
\left(\mathrm{m}^{2} / \mathrm{g}\right)\end{array}$ & $\begin{array}{c}\text { Crystallite size } \\
(\mathrm{nm})\end{array}$ & $\begin{array}{c}\text { Cell parameter } \\
(\mathrm{nm})\end{array}$ & TOSC $^{*}$ \\
\hline $\mathrm{C}$ & 41 & 7.3 & 0.541 & 0.04 \\
$\mathrm{CZ}$ & 84 & 4.5 & 0.535 & 0.16 \\
$\mathrm{CT}$ & 85 & 5.5 & 0.537 & 0.18 \\
$\mathrm{CZA}$ & 146 & 4.0 & 0.529 & 0.42 \\
$\mathrm{CTA}$ & 148 & 3.7 & 0.538 & 0.36 \\
$\gamma-\mathrm{Al}_{2} \mathrm{O}_{3}$ & 127 & - & - & 0.00 \\
\hline
\end{tabular}

${ }^{*}$ TOSC $=$ Weight loss $\times 10 / 32$.

$\mathrm{Tb}^{3+}$. The lattice parameters of the CZA sample is slightly smaller than that of the $\mathrm{CZ}$ this could be due to the incorporation of more amount of $\mathrm{Zr}$ into the ceria lattice. The lattice parameter of the CTA sample is slightly larger than that of the unsupported ceria-terbia of the same chemical composition $(0.537 \mathrm{~nm})$. This indicates the presence of small excess amount of trivalent cations in the lattice of the resultant supported oxide, either namely $\mathrm{Ce}^{3+}$ and $\mathrm{Tb}^{3+}$ or both, having cationic radii of 0.114 and $0.104 \mathrm{~nm}$, respectively. Being these trivalent cations are bigger than the tetravalent $\mathrm{Ce}^{4+}$ (cationic radius of $0.097 \mathrm{~nm}$ ), they can compensate for the contraction of the ceria lattice due to the presence of smaller $\mathrm{Tb}^{4+}$ (cationic radius of $0.088 \mathrm{~nm}$ ). In the case of $\mathrm{Al}_{2} \mathrm{O}_{3}$-supported samples, the formation of $\mathrm{CeAlO}_{3}$ is also not observed. It could be inferred from XRD results that the deposition coprecipitation adopted in the present study may be a good method to obtain highly dispersed ceria-zirconia and ceria-titania mixed oxides over the supports without the formation of inert compounds.

\subsection{RS result}

The RS is widely used to investigate the oxygen lattice vibration in fluorite-type oxides. In the present study, RS are collected by using ultraviolet wavelength excitation (325 $\mathrm{nm})$ which enables selective detection of the crystal structure surface region. Therefore, we conclude that the bands are attributed to relative contribution of the oxygen vacancies from the surface region [17]. The UV Raman spectra of CZ, CT, CZA, and CTA are shown in Fig. 2. The UV Raman of pure ceria is also included in the figure as a reference. For the space group Fm3m, the only Raman active mode $\left(\mathrm{F}_{2 \mathrm{~g}}\right)$ is centered at around $460 \mathrm{~cm}^{-1}$ could be attributed to the $F_{2 g}$ Raman-active mode characteristic of the fluorite cubic type lattice, which can be viewed as a symmetric breathing mode of the oxygen atoms around cerium ions. The band at this region is due to symmetric $\mathrm{O}-\mathrm{Ce}-\mathrm{O}$ stretching mode [18]. This band is sensitive to any disorder in the oxygen sublattice and the presence of this band indicates that all samples exhibit a global cubic fluorite type

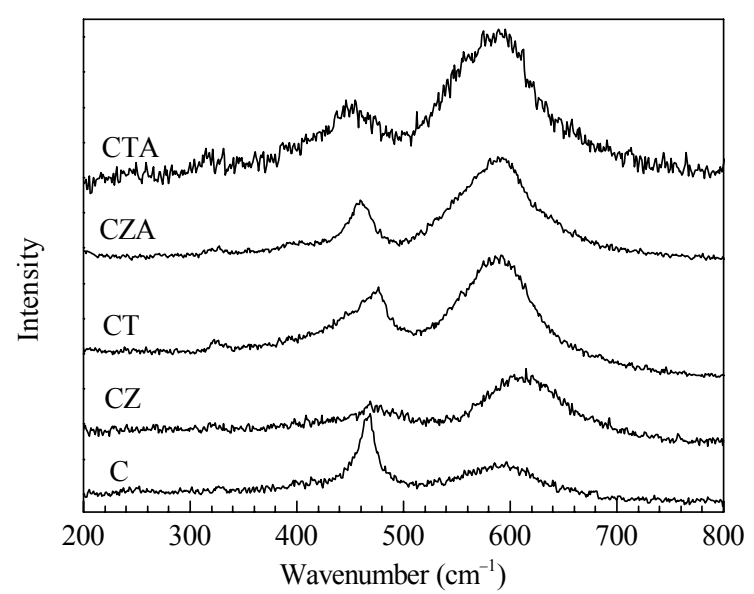

Fig. 2. UV Raman spectra of the $\mathrm{C}, \mathrm{CZ}, \mathrm{CT}, \mathrm{CZA}$, and CTA samples calcined at $773 \mathrm{~K}$.

structure in line with XRD results. The intensity of the Raman band depends on several factors including grain size, morphology, etc. [19]. No Raman lines due to $\mathrm{ZrO}_{2}$ and $\mathrm{Tb}_{4} \mathrm{O}_{7}$ were observed corroborating with the XRD results indicating the formation of solid solution. The presence of a prominent broad band at $\sim 600 \mathrm{~cm}^{-1}$ could be attributed to a non-degenerate Raman inactive longitudinal optical (LO) mode of ceria, which arises due to relaxation of symmetry rules. Interestingly, the peak at $\sim 600 \mathrm{~cm}^{-1}$ for supported and unsupported CT samples is relatively more pronounced compared to supported and unsupported $\mathrm{CZ}$, respectively which could attributed to presence of more number of reducible sites $\left(\mathrm{Ce}^{3+} / \mathrm{Tb}^{3+}\right)$ located near surface region. Within the CT and CTA, the CTA has shown a high intense band compared to CT. These sites may facilitate the adsorption and desorption of gaseous oxygen and thereby could offer better activity for oxidation reaction. The nature of this band may be due to the resonance enhancement of the Raman scattering cross section under UV excitation. The absence of any other Raman features provided one more inference that alumina is not forming any compound with cerium, zirconium and terbium oxides.

\subsection{HRTEM and BET surface area}

In order to substantiate the observations made from XRD and Raman measurements and to uncover the information on the nanometer sizes of the investigated oxide samples, HRTEM analyses were undertaken and the representative micrographs are shown in Fig. 3. As can be noted from these micrographs, the particle size of all the samples are observed to be in the range of 5-8 $\mathrm{nm}$. In all the images, small and well faceted mixed oxide particles deposited on the surface of larger surface area support are clearly visible. The mixed oxide crystals seem to be well distributed on the 
support, i.e., homogeneous in nature. HRTEM micrographs provide a better perception of the size and dispersion of these mixed oxide particles. As observed, the mixed oxide particles are agglomerated in nature. Plain faces representing the support could not be seen suggesting the amorphous nature of it. This observation is supported by the XRD results as well. The shapes of the particles are more or less cuboctahedral. There is observed some sort of amorphous region in the case of CTA sample. Table 1 lists the information about the specific surfaces of various catalysts along with $\gamma-\mathrm{Al}_{2} \mathrm{O}_{3}$ obtained from $\mathrm{N}_{2}$ physisorption measurements. The CZ and CT samples prepared under identical conditions by adopting the same preparation technique exhibited surface areas of 84 and $85 \mathrm{~m}^{2} / \mathrm{g}$, respectively. When these are dispersed over the alumina support, the surface area is increased. This observation further revealed the ability of alumina support to stabilize the $\mathrm{CZ}$ and $\mathrm{CT}$ against sintering.

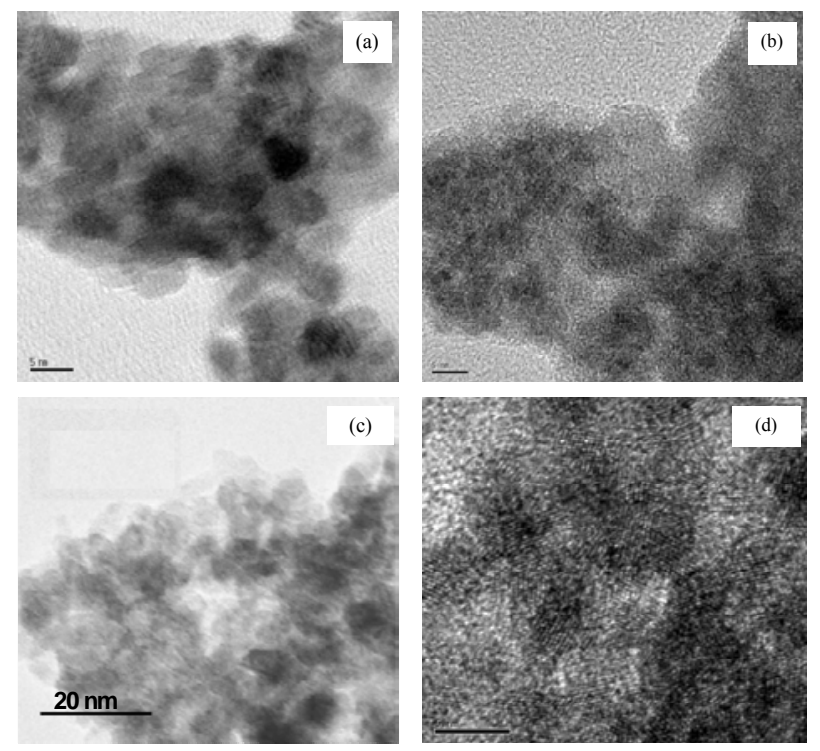

Fig. 3. HRTEM images of the CZ (a), CT (b), CZA (c), and CTA (d) samples calcined at $773 \mathrm{~K}$.

\subsection{XPS result}

The Ce $3 d$ core level spectra of different samples are presented in the Fig. 4 . As can be seen from figure the $3 d_{3 / 2}$ and $3 d_{5 / 2}$ (represented as $\mathrm{U}$ and $\mathrm{V}$, respectively) contributions. The peak at $\sim 916.6 \mathrm{eV}$ (U'") is mainly correspond to the $\mathrm{Ce}^{4+}$ state. The U'" peak is the most convenient feature to follow the progressive reduction of $\mathrm{Ce}$, since it does not overlap with others. The peaks of $\mathrm{Ce}^{3+}\left(\mathrm{V}^{0}, \mathrm{U}^{0}\right)$ are generally noticed at around 881 and $898 \mathrm{eV}$, respectively. Here, it can be seen that the latter peak is overlapping with V'". The satellites to these features ( $\mathrm{V}^{\prime}$ and $\mathrm{U}^{\prime}$ ) occur at 885.9 and $904.2 \mathrm{eV}$, respectively. It can be observed that the shoulder

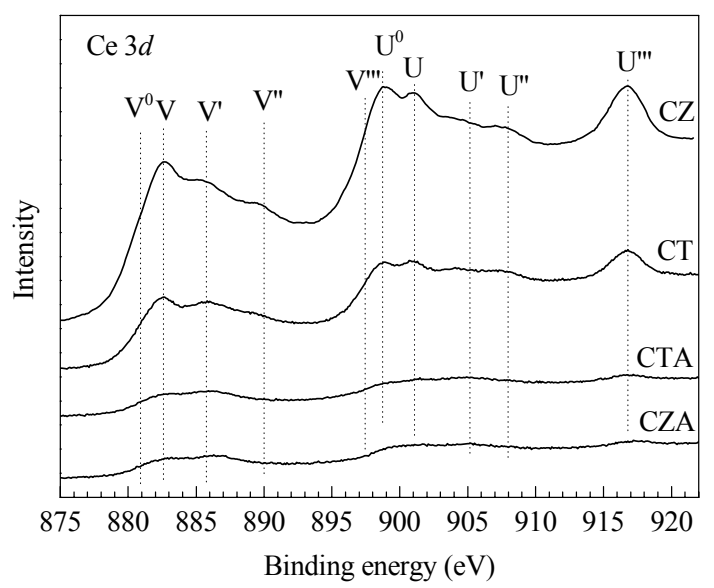

Fig. 4. XPS spectra of the CZ, CT, CZA, and CTA samples calcined at $773 \mathrm{~K}$.

above $881 \mathrm{eV}$ is made up of a mixture of $\mathrm{V}$ and $\mathrm{V}^{0}$ features and the usual good separation between $\mathrm{V}$ and V" (characteristic of only $\mathrm{Ce}^{4+}$ state) is prevented by a significant intensity of $\mathrm{V}^{\prime}$ indicating the presence of $\mathrm{Ce}^{3+}$ in the sample. The presence of the $\mathrm{Ce}^{4+}$ state is supported by a considerable intensity of the U'" peak. Thus, on the surface of the samples, the concentrations of both $\mathrm{Ce}^{4+}$ and $\mathrm{Ce}^{3+}$ are quite comparable. A progressive reduction of $\mathrm{Ce}^{4+}$ into $\mathrm{Ce}^{3+}$ oxidation state results with a decrease in the $U^{\prime \prime}$ intensity and an increase in $\mathrm{V}^{\prime}$ and $\mathrm{U}^{\prime}$ at the expense of $\mathrm{V}^{\prime \prime}$ and $\mathrm{U}^{\prime \prime}$ for supported samples compared with unsupported samples [15]. Particularly, CTA has shown significant intensity ratio $\left(\mathrm{Ce}^{3+} / \mathrm{Ce}^{4+}\right)$ among the investigated samples conferring its high reducibility.

\subsection{OSC result}

The OSC of all the samples are given in the Table 1. It is known that fluorite-type structure plays an important role for the OSC. In general terms, from pure ceria $\rightarrow$ ceria solid solutions $\rightarrow$ supported ceria solid solutions the OSC is increased $[10,13]$. Specificity of mixed oxides for oxygen storage was shown to be due to the participation of bulk oxygen. Hence, another important point, which can be drawn from the obtained results, is that the oxygen storage takes place not only at the surface but also in the bulk. In the present investigation the $\mathrm{CZ}$ and $\mathrm{CT}$ solid solutions exhibited higher OSC compared with pure ceria that could be due to the bulk oxygen availability in the solid solutions. Among these solid solutions, the CT has shown significantly high OSC compared with $\mathrm{CZ}$ which could be due to the redox nature of $\mathrm{Tb}$ and therefore more amount of oxygen contributed to OSC. Further, the supported solid solutions exhibited almost 8-10 times higher OSC than that obtained for pure ceria sample, since the $\gamma-\mathrm{Al}_{2} \mathrm{O}_{3}$ support 
showed no OSC activity within the experimental conditions. The increase in the OSC of the supported sample may be due to an increased dispersion of the mixed oxide over the support with significant increase in the surface area. Within CZA and CTA samples, the CZA has shown higher OSC, this could be due to the more amount of $\mathrm{Zr}$ incorporation (from XRD) into the ceria lattice after depositing it on to the alumina support that consequently enhances the reducible cerium ions $\left(\mathrm{Ce}^{4+}\right)$.

\subsection{CO oxidation activity}

The catalytic activities of CZ, CT, CZA, and CTA were tested for $\mathrm{CO}$ oxidation. The activity measurements were performed at normal atmospheric pressure and the conversion of CO was evaluated as earlier reports [15]. The conversion of $\mathrm{CO}$ as a function of reaction temperature is presented in Fig. 5. It is evident from figure that both supported and unsupported CT samples exhibited better activity in terms of total conversion as well as light-off temperature (temperature at $50 \%$ conversion). Both CTA and CT samples exhibited maximum conversion at approximately 730 and $773 \mathrm{~K}$ with light-off temperatures around 604 and 621 $\mathrm{K}$, respectively, whereas $\mathrm{CZ}$ and CZA samples have shown light-off temperatures above $650 \mathrm{~K}$, and maximum $\mathrm{CO}$ conversion beyond $750 \mathrm{~K}$. The catalytic efficiency order was found to be $\mathrm{CZ}<\mathrm{CZA}<\mathrm{CT}<\mathrm{CTA}$. This shows the superiority of the CTA sample over other samples. It is known from the literature that OSC plays a major role but in the present case, the OSC is not in the same order with activity [13]. From the table, CZA has shown high OSC nevertheless CT and CTA have shown high activity. During the oxidation of $\mathrm{CO}$, the rapid transformation of adsorbed $\mathrm{CO}$ in to $\mathrm{CO}_{2}$ strongly depends on the rate of uptake/release of lattice oxygen. In fact, the oxygen uptake/release depends not only on total OSC but also on the number of redox sites

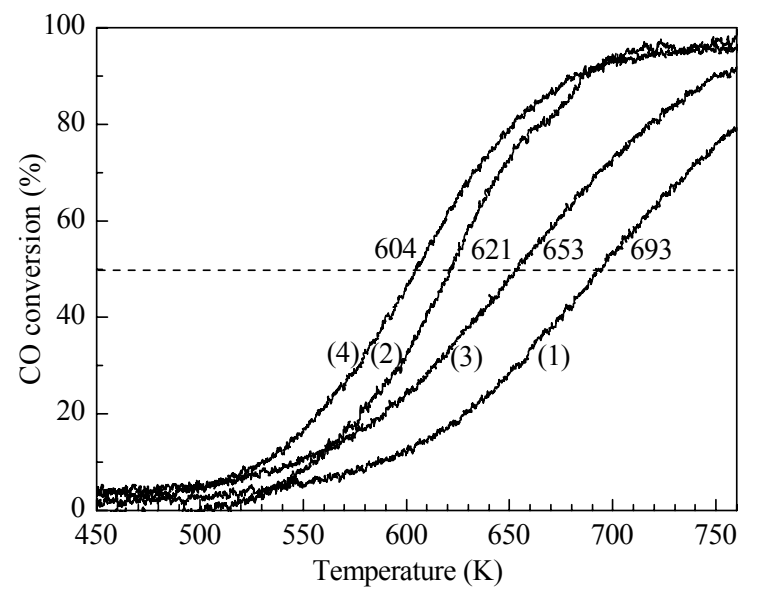

Fig. 5. Conversion of $\mathrm{CO}$ versus temperature for $\mathrm{CZ}$ (1), CT (2), CZA (3), and CTA (4) samples calcined at $773 \mathrm{~K}$. and rate of redox cycles as well [20]. The number of redox sites are unaltered (both $\mathrm{Ce}^{3+/ 4+}$ and $\mathrm{Tb}^{3+/ 4+}$ ions act as redox sites) for $\mathrm{CT}$ and $\mathrm{CTA}$ sample whereas for CZA $\left(\mathrm{Ce}_{0.5} \mathrm{Zr}_{0.5} \mathrm{O}_{2}\right.$ confirmed from XRD) these are decreased. Moreover, in the $\mathrm{Zr}$ doped ceria oxygen vacancies are trapped by the high electronegative $\mathrm{Zr}$ ions, hence oxygen transfer rate decreased [21]. All these parameters together make CZA less active than CTA even less than CT. The high activity of CTA over other samples is also correlated with the combination of facts which include (i) small crystallite size, high surface area and (ii) more reducibility as supported by XRD, HRTEM, and XPS. Thus, the combined use of XRD, RS, XPS, and HRTEM techniques provided interesting information regarding the influence of support on the CO oxidation activity of highly dispersed ceria-terbia solid solution. From the obtained results it is obvious that the CTA sample has the promising characteristics to be used as a catalyst for $\mathrm{CO}$ oxidation.

\section{Conclusions}

Ceria-zirconia and ceria-terbia solid solutions dispersed over $\mathrm{Al}_{2} \mathrm{O}_{3}$ support possessing high specific surface area and good thermal stability were synthesized by a deposition coprecipitation method. The X-ray diffraction analysis revealed the crystal faces corresponding to a fluorite-type structure of investigated samples and there is no indication of formation of other compounds such as $\mathrm{CeAlO}_{3}$ for supported samples. Raman spectroscopy studies suggest formation of oxygen vacancies, and lattice defects in various samples, which are important from the catalytic point of view. The high resolution transmission electron microscopy studies revealed the nanocrystalline nature of the dispersed ceria-terbia and ceria-zirconia solid solutions. The catalytic activity of the synthesized samples for $\mathrm{CO}$ oxidation was found to follow the order alumina-supported ceria-terbia $>$ ceria-terbia $>$ alumina-supported ceria-zirconia $>$ ceria-zirconia. In terms of conversion as well as light-off temperatures $(50 \%$ conversion $)$, the alumina-supported ceria-terbia is remarkably better than all other samples. The substantially high activity could be due to the formation of solid solution and more defect sites in its crystal lattice, better dispersion of the active phase over the support, more number of redox sites and high rate of redox cycles. Thus, alumina-supported ceria-terbia could be a promising catalyst for use in the TWC formulations.

\section{References}

1 Chen J, Zhu J, Zhan Y, Lin X, Cai G, Wei K, Zheng Q. Appl Catal A, 2009, 363: 208

2 Damyanova S, Pawelec B, Arishtirova K, Martinez Huerta M 
V, Fierro J L G. Appl Catal A, 2008, 337: 86

3 Boaro M, Giordano F, Recchia S, Santo V D, Giona M, Trovarelli A. Appl Catal B, 2000, 52: 225

4 Sinha A K, Suzuki K. J Phys Chem B, 2005, 109: 1708

5 Krishna K, Bueno-Lopez A, Makkee M, Moulijn J A. Appl Catal B, 2007, 75: 189

6 Wilkes M F, Hayden P, Bhattacharya A K. J Catal, 2003, 219: 295

7 Machida M, Kurogi D, Kijima T. Chem Mater, 2000, 12: 3165

8 Li G, Smith R L, Inomata H. J Am Chem Soc, 2001, 123: 11091

9 Bernal S, Blanco G, Cauqui M A, Martin A, Pintado J M, Galtayries A, Sporken R. Surf Interface Anal, 2000, 30: 85

10 Reddy B M, Thrimurthulu G, Katta L, Yamada Y, Park S E. $J$ Phys Chem C, 2009, 113: 15882

11 Reddy B M, Saikia P, Bharali P, Yamada Y, Kobayashi T, Muhler M, Grünert W. J Phys Chem C, 2008, 112: 16393

12 Gong Z, Jonathan H, Gorte R J. Appl Catal A, 2008, 335: 153
13 Reddy B M, Lakshmanan P, Bharali P, Saikia P, Thrimurthulu G, Muhler M, Grünert W. J Phys Chem C, 2007, 111: 10478

14 Ozawa M, Matuda K, Suzuki S. J Alloys Compd, 2000, 303: 56

15 Reddy B M, Saikia P, Bharali P, Park S-E, Muhler M, Grünert W. J Phys Chem C, 2009, 113: 2452

16 Katta L, Sudarsanam P, Thrimurthulu G, Reddy B M. Appl Catal B, 2010, 101: 101

17 Luo M F, Yan Z L, Jin L Y, He M. J Phys Chem B, 2006, 110: 13068

18 Yashima M, Arashi H, Kakihana M, Yoshimura M. J Am Ceram Soc, 1994, 77: 1067

19 Hernandez W Y, Centeno M A, Romero-Sarria F, Odriozola J A. J Phys Chem C, 2009, 113: 5629

20 Liu X, Zhow K, Wang L, Wang B, Li Y. J Am Chem Soc, 2009, 131: 3140

21 Balducci G, Islam M S, Kaspar J, Fornasiero P, Graziani M. Chem Mater, 2000, 12: 677 